visual and olfactive contact with sows) and two diets (R1 balanced control and R2 with an excess of tryptophan) were compared. Neither rearing conditions nor diets had a significant effect on growing performance or male genital tract development. A tendency to lower incidence of boar taint in pigs fed with diet R2 (32 to 40 p. 100 of opinions vs 47 to $58 \mathrm{p} .100$ for diet $\mathrm{R} 1 ; \mathrm{p}<0.10$ ). This result is contrary to the hypothesis according to which an excess of tryptophan could lead to higher synthesis and storage of skatole (compound having a faecal odour) in fat. In other respects, there was a significant relationship between boar taint intensity and weight of bulbourethral glands $(\mathrm{r}=+0.59 ; \mathrm{p}<0.01)$. The weight of these glands could be a simple criterion to be used on the slaughter line for an easy detection of suspect carcasses needing further testing.

\title{
Consumer testing of fresh meat from young boars : relationships with androstenone content in fats
}

\author{
B. DESMOULIN et M. BONNEAU
}

I.N.R.A., Station de Recherches sur l'Elevage des Porcs, Centre de Rennes-Saint-Gilles, F 35590 L'Hermitage

Consumer testing of roasts and ribs was made in 55 French families from the area of Paris. Large White young boars were raised according to different rearing conditions either with or without females in adjacent pens and either in individual or collective boxes. The animals were slaughtered at $95 \mathrm{~kg}$ and 167 days or $105 \mathrm{~kg}$ and 185 days, on an average. Results concerning the storage of androstenone in backfat have been published previously (BONNEAU and Desmoulin, 1980). The results of 229 consumption tests are reported in table 1 for boar meat and control meat from castrates and females according to cuts and main criteria, i.e. cooking odours or taste at the family table.

1) The main cooking odour difference $\left(\Delta_{\mathrm{H} Y}\right)$ corresponded to the unpleasant odours recorded in boar meat (37-39 p. 100) as compared with control meat (3-9 p. 100). There was tendency to a greater number of unpleasant assessements for boars reared with females. However, the largest differences were registered according to slaughter weights, especially for taste of boar meats : 34 p. 100 unpleasant rating at $105 \mathrm{~kg}$ versus 18 at $95 \mathrm{~kg}$.

2) According to androstenone content in fats, a clear threshold of unacceptable ccoking odours was noticed for meats above $1 \mathrm{ppm}$ androstenone : $18 \mathrm{p} .100$ of the total boar production is involved in this refusal by the consumers. On the other hand, there were tendencies for an increase in critical notations for meat taste above $0.5 \mathrm{ppm}$ androstenone ; $45 \mathrm{p} .100$ of the total boar production may be concerned. The strong taste was generally registered, but the criticism was less marked as for cooking odours.

The role of androstenone is discussed on account of the different off flavours of boar meat during the cooking procedure.

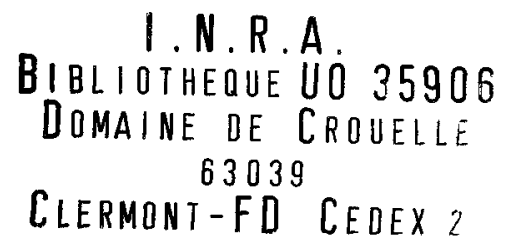

